\title{
O ARQUIVISTA COMO MODERNO PROFISSIONAL DA INFORMAÇÃO: ANÁLISE DE COMPETÊNCIAS À LUZ DA IITERATURA E DA FORMAÇÃO CURRICULAR
}

THE ARCHIVIST AS A MODERN INFORMATION PROFESSIONAL: ANALYSIS OF SKILLS IN LIGHT OF LITERATURE AND CURRICULAR TRAINING

EL ARCHIVERO CON INFORMACIÓN PROFESIONAL MODERNA: ANÁLISIS DE COMPETENCIA EN LA LUZ DE LA LITERATURA Y PLAN DE ESTUDIOS DE FORMACIÓN

1Jorge Santa Anna

Universidade Federal do Espírito Santo

\section{Correspondência}

${ }^{1}$ Jorge Santa Anna

Universidade Federal do Espírito Santo.

Vitória, ES.

E-mail: jorjao20@yahoo.com.br

ORCID: http://orcid.org/0000-0002-0709-3639

Submetido em: 13-09-2016

Aceito em: 13-02-2017

Publicado: 20-03-2017

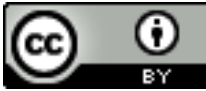

JITA: AC. Relationship of LIS with other fields. 
RESUMO: As demandas e exigências do mercado de trabalho no âmbito das profissões da informação desencadeiam necessidades de aprimoramento das práticas profissionais, por conseguinte, remetem à reforma curricular, haja vista formar profissionais competentes que atendam as necessidades sociais. Os arquivistas, ao serem categorizados como profissionais da informação, também se inserem nesse contexto, devendo adquirir status de um Moderno Profissional da Informação (MIP). Sendo assim, este estudo analisa as competências do MIP relacionando-as ao arquivista, com base na literatura e na formação curricular. Investiga na literatura o que vem sendo publicado sobre o MIP; compara as competências do MIP com o arquivista; e investiga essas competências no âmbito da formação arquivística. Metodologicamente, realizou-se revisão na literatura sobre as competências do MIP e suas relações com os arquivistas e análise a dez currículos de escolas de Arquivologia do Brasil, haja vista detectar disciplinas voltadas para construção das competências do MIP. Após pesquisa teórica e documental, percebeu-se que a maioria dos estudos realizados $(80 \%)$ compara o MIP ao bibliotecário. A literatura é escassa (10\%) ao direcionar o MIP ao arquivista, como também sem delineá-lo a profissionais específicos (10\%). Quanto à formação acadêmica, as escolas, em linhas gerais, disponibilizam disciplinas, cujo enfoque curricular contempla as quatro competências do MIP. Detectou-se que as escolas reconhecem a necessidade de ampliar as competências dos arquivistas, a ponto de eles se tornarem MIPs, haja vista adequarem-se aos novos desafios impostos pelo mercado de trabalho.

PAlavRAS-ChaVE: Ciência da Informação. Arquivologia. Arquivista. Moderno Profissional da Informação. Competências profissionais.

ABSTRACT: The demands and demands of the labor market in the field of information professions trigger the need to improve professional practices, therefore, refer to the curricular reform, due to the formation of competent professionals that meet the social needs. Archivists, when categorized as information professionals, also fit into this context, and must acquire the status of a Modern Professional Information (IPM). Thus, this study analyzes the competencies of IPM relating them to the archivist, based on literature and curricular training. Investigates in literature what has been published about IPM; Compares MIP's competencies with the archivist; And investigates these skills in the field of archival training. Methodologically, a review of the competencies of the MIP and its relations with the archivists and analysis of ten curricula of Brazilian archival schools was carried out, in order to detect disciplines focused on the construction of IPM competencies. After theoretical and documentary research, it was noticed that most of the studies $(80 \%)$ compare the MIP to the librarian. The literature is scarce $(10 \%)$ by directing the IPM to the archivist, but also without delineating it to specific professionals (10\%). As for the academic formation, the schools, in general lines, offer disciplines, whose curricular approach contemplates the four competences of the MIP. It was found that schools recognize the need to extend the skills of archivists to the point where they become IPMs, in order to adapt to the new challenges posed by the labor market.

KEYWORDS: Information Science. Archival. Archivist. Modern Information Professional. Professional skills.

RESUMEN: Las demandas y requerimientos del mercado de trabajo en el campo de las profesiones de la información desencadenan las necesidades de mejora de la práctica profesional, por tanto, se refiere a la reforma de los programas, teniendo en cuenta la formación de profesionales competentes que cumplan con las necesidades sociales. Archiveros, se las califique como profesionales de la información, también cae dentro de ese contexto, debe adquirir la condición de Información Profesional Moderno (MIP). Por lo tanto, este estudio se analizan las habilidades MIP relacionándolos con el archivero, basado en el plan de estudios de la literatura y la formación. Investiga la literatura que se ha publicado en el MIP; compara las habilidades de MIP con el archivero; e investiga estas habilidades dentro de la capacitación en archivos. Metodológicamente, hubo revisión de la literatura sobre las habilidades del MIP y sus relaciones con los archiveros y análisis de los planes de estudio a diez escuelas Archivología en Brasil, dada detectar disciplinas destinadas a la construcción de las habilidades MIP. Después de la investigación teórica y documental, se observó que la mayoría de los estudios (80\%) compara el MIP al bibliotecario. La literatura es escasa (10\%) para dirigir el MIP al archivero, sino también sin contorno a los profesionales específicos (10\%). En cuanto a los académicos, escuelas, en general, proporcionar disciplinas cuyo enfoque curricular incluye cuatro habilidades MIP. Se encontró que las escuelas reconocen la necesidad de ampliar los poderes de archiveros hasta el punto de que se conviertan precios mínimos, dado ajustarse a los nuevos retos que plantea el mercado laboral.

PAlabras Clave: Ciencias de la Información. Archivología. Archivero. Moderna profesional de la información. Habilidades profesionales.

\begin{tabular}{c|c|c|c|c|c}
\hline (C) RDBCI: Rev. Digit. Bibliotecon. Cienc. Inf. & Campinas, SP & v.15 & n.2 & p. 289-307 & maio/ago. 2017 \\
\hline
\end{tabular}




\section{INTRODUÇÃO}

Diversos fatores contribuíram (e contribuem) na redefinição de práticas profissionais, exigindo maior conhecimento e ampliação de competências em todas as profissões da sociedade contemporânea. De modo geral, as transformações sociais redesenham a figura de um profissional que consiga atender as exigências de um mercado em evolução, competitivo, instável, mutante e globalizado.

Os fatores mais influentes no constante aprimoramento das práticas profissionais, sobretudo no que se refere ao mercado da informação, diz respeito ao avanço tecnológico e ao surgimento da explosão bibliográfica, acontecimentos esses que marcaram a inauguração do século XXI e terceiro milênio.

Há consenso na literatura sobre a interferência desses fatores no contexto da profissionalização, requerendo o constante aprimoramento daqueles que desejam permanecer atuante no mercado de trabalho. Segundo Mac Garry (1999), vivemos hoje um "tsunami" de informações, graças aos novos recursos tecnológicos que foram inseridos na sociedade. Solla Price (1993) afirma que o acúmulo informacional atingiu o ápice nestas últimas décadas, no entanto, trata-se de um longo processo iniciado após a invenção da imprensa.

Certamente, com tanta informação sendo gerada e disponibilizada, impactos surgem, havendo necessidade de alternativas inovadoras, no sentido de viabilizar técnicas de gestão da informação, transformando-a em conhecimento. Para tanto, os profissionais precisam adquirir novas competências, aprimorando seus fazeres, técnicas e metodologias. Fica evidente que “numa época de tal 'explosão de conhecimento' e o consequente aumento da sobrecarga ou 'excesso de informação', [...] a especialização se tornou cada vez mais necessária” (BURKE, 2012, p. 203).

As mudanças sociais condicionam a consolidação de novos paradigmas que sustentam as diversas áreas do conhecimento. No âmbito da Ciência da Informação, por exemplo, esses paradigmas vêm sendo construídos em face da transferência, disseminação e uso da informação, além dos aspectos ligados à adequação dos produtos e serviços informacionais ao usuário da informação (ARAÚJO, 2014).

No contexto da Arquivologia, os paradigmas atuais são reformulados a partir do enfoque na informação arquivística (TOGNOLLI, 2012), nos serviços informacionais prestados aos usuários (JARDIM; FONSECA, 2004), e, principalmente, através da transfiguração dos objetivos do arquivo que deixa de atentar-se, tão somente à custódia, para ater-se ao acesso, adentrando-se a um contexto pós-custodial (COOK, 2012).

Com efeito, as mudanças paradigmáticas nas áreas do saber provocam mudanças nas práticas profissionais, exigindo que as competências profissionais sejam reconstruídas, além

\begin{tabular}{l|l|l|l|l|l} 
(C) RDBCI: Rev. Digit. Bibliotecon. Cienc. Inf. & Campinas, SP & v.15 & n.2 & p. 289-307 & maio/ago. 2017 \\
\hline
\end{tabular}


da aquisição de habilidades múltiplas, ampliando as potencialidades do profissional, podendo solucionar problemas e atender complexas demandas.

Os profissionais que estão inseridos em um mercado mutante e desafiador como o da atualidade ampliam suas competências, habilidades e conhecimentos, através da capacitação ou formação continuada. Esse é um tema em destaque e considerado como de extrema importância para a adequação profissional.

Além da especialização defendida por Burke (2012), muitos problemas são solucionados a partir da interação entre as áreas, desencadeando trabalhos multiprofissionais. No caso da Ciência da Informação, os profissionais da informação compartilham auxílios entre si, de modo que, mesmo atuando em áreas específicas, esses profissionais ajudam-se mutuamente na resolução de problemas.

Mason (1990) considera como profissionais da informação, aqueles cujos fazeres colocam-se a serviço de selecionar, tratar e disponibilizar a informação, independente de seu suporte e contexto, no momento que o usuário precisa. Constitui o rol desses profissionais: os administradores, museólogos, arquivistas, bibliotecários, dentre outros.

De modo particular, os profissionais que possuem como objeto de estudo a informação são os bibliotecários, os museólogos e os arquivistas. Essa trindade, segundo Smit (2000), constitui o que a autora denomina de "as três Marias", tendo cada uma seu escopo de atuação, mas apresentando forte tendência interdisciplinar.

Influenciados pelos desafios da sociedade moderna, inúmeros questionamentos são evidenciados: como adequar-se a um mercado instável? Como os profissionais da informação atuarão diante dos novos desafios impostos? Como ser um profissional reconhecido e que trabalhe em conjunto? Tendo esses questionamentos em voga, a extinta Federação Internacional de Documentação (FID) realizou estudo voltado a delimitar um perfil profissional para os profissionais que lidam com a informação.

A partir desses questionamentos, a FID financia projeto de pesquisa, conduzido por meio dos estudos da pesquisadora cubana Pojuan Dante (1993, 2000). Através desses estudos, surgiu, nas últimas décadas do século passado, um novo termo para caracterizar o profissional da informação, em face das transformações, denominado de Moderno Profissional da Informação (MIP). Para ser categorizado como MIP, o profissional deve apresentar características específicas que o torne capaz de adequar-se à sociedade. Segundo Pojuam Dante (1993), a flexibilidade, inovação, imaginação e criatividade são alguns dos ingredientes vitais para que se atinja o status de MIP.

O ponto forte das discussões em torno do MIP está no ano de 2000, através do IV Encontro de Diretores das Escolas de Biblioteconomia e Ciência da Informação do Mercosul,

\begin{tabular}{l|l|l|l|l|l}
\hline (C) RDBCI: Rev. Digit. Bibliotecon. Cienc. Inf. & Campinas, SP & v.15 & n.2 & p. 289-307 & maio/ago. 2017 \\
\hline
\end{tabular}


realizado no ano de 2000, em Montevidéu, momento em que foram determinadas as seguintes competências profissionais necessárias para que profissionais da informação fossem considerados MIP: competências de comunicação, técnico-científica, gerenciais e sociais e políticas.

A Arquivística, especificamente, insere-se nesse contexto, por ser uma área voltada para a gestão da informação produzida pelas sociedades, ao longo do tempo, preocupando-se com a memória social e cultural e, ao mesmo tempo, viabilizando a produção de conhecimentos, contribuindo com o tratamento, armazenamento, recuperação, enfim, auxilia o fluxo documental.

Os arquivistas, considerados como profissionais da informação, tendo em vista os desafios impostos pela sociedade e diante dos paradigmas que sustentam a área, devem reformular seus fazeres, adquirindo competências que vão além daquelas ditas como tradicionais, ou seja, àquelas voltadas apenas para a custódia e gestão de arquivos.

Afirma Lopes (2009), que a Arquivística é uma área relativamente nova e está em ascensão, sobretudo a partir da modernização administrativa. O mercado competitivo viabiliza às organizações encontrar na informação orgânica e sua efetiva gestão, uma estratégia válida para atingir níveis competitivos.

O autor supracitado considera que o arquivista da sociedade moderna não é o mesmo de décadas atrás. Ao contrário, ele deve remodelar-se para não ser esquecido, adquirindo novos conhecimentos a fim de adequar-se. Deve ser um produtor de conhecimento, um profissional hermeneuta, que através da pró-atividade, inovação e criatividade atue de forma crítica e questionadora, modificando realidades e problemas complexos.

Para tanto, o arquivista deve possuir competências específicas a ponto de caracterizarse como MIP, tendo em vista adequar-se às novas necessidades e ser reconhecido no mercado como um profissional atuante e fundamental para desenvolvimento de instituições e da nação.

Fica claro que para haver adequação às transformações, a formação curricular deve ser reestruturada, levando em considerações os desafios impostos pela atualidade. Valentim (2000) considera que as escolas de Ciência da Informação devem pautar em um viés formativo que priorize as demandas do mercado, de modo a potencializar os futuros profissionais a reconhecerem suas competências e encontrar diferentes segmentos de atuação.

Sendo assim, esta pesquisa objetiva analisar as competências do MIP relacionando-o aos arquivistas, tendo como parâmetro de análise a literatura e a formação curricular. Para tanto, investiga na literatura o que vem sendo publicado sobre o MIP; compara as competências do MIP com os arquivistas; e, por fim, investiga a formação das competências do MIP no âmbito da formação arquivística. 
Como metodologia, realizou-se, primeiramente, revisão na literatura sobre as competências do MIP e suas relações com os arquivistas. Em seguida, através de pesquisa documental, analisaram-se dez currículos de escolas de Arquivologia do Brasil, haja vista detectar disciplinas voltadas para construção das competências do MIP.

\section{O MODERNO PROFISSIONAL DA INFORMAÇÃO NO ÂMBITO DA ARQUIVÍSTICA: DISCUSSÃO TEÓRICA}

No intuito de investigar o que vem sendo publicado na Literatura sobre MIP, procedeuse à técnica de levantamento bibliográfico através da base de dados Brapci ${ }^{1}$. Utilizando-se procedimentos específicos de busca e recuperação da informação na base Brapci, obtiveramse, através do descritor "Moderno Profissional da Informação" dez trabalhos recuperados. A seleção restringiu-se, tão somente, a localizar apenas artigos de periódicos. O quadro 1 expõe o título dos artigos, autoria, ano, objetivo geral e os principais resultados atingidos.

Quadro 1. Estudos recuperados acerca do Moderno Profissional da Informação a partir da busca realizada na base Brapci

\begin{tabular}{|c|c|c|c|c|c|}
\hline $\begin{array}{c}\text { Base de } \\
\text { dados }\end{array}$ & Título & Autoria & Ano & Objetivo geral & Resultado alcançado \\
\hline & $\begin{array}{c}\text { A formação do } \\
\text { bibliotecário para } \\
\text { atuar em bibliotecas } \\
\text { virtuais: uma } \\
\text { questão a } \\
\text { aprofundar }\end{array}$ & $\begin{array}{l}\text { MADUREIRA, } \\
\text { Helania } \\
\text { Oliveira; } \\
\text { VILARINHO, } \\
\text { Lúcia Regina } \\
\text { Goulart }\end{array}$ & 2010 & $\begin{array}{l}\text { Analisar a formação de } \\
\text { bibliotecários para o } \\
\text { trabalho em bibliotecas } \\
\text { virtuais (BV), }\end{array}$ & $\begin{array}{l}\text { A formação do bibliotecário } \\
\text { está longe de privilegiar o } \\
\text { perfil do moderno } \\
\text { profissional da informação }\end{array}$ \\
\hline & $\begin{array}{l}\text { O bibliotecário } \\
\text { como agente } \\
\text { histórico: do } \\
\text { "humanista" ao } \\
\text { "moderno } \\
\text { profissional da } \\
\text { informação" }\end{array}$ & $\begin{array}{l}\text { SILVEIRA, } \\
\text { Fabrício José } \\
\text { Nascimento da }\end{array}$ & 2008 & $\begin{array}{l}\text { Analisa, a partir de uma } \\
\text { perspectiva sócio- } \\
\text { histórica, o conjunto das } \\
\text { atividades que demarcam } \\
\text { o fazer profissional dos } \\
\text { bibliotecários }\end{array}$ & $\begin{array}{l}\text { É preciso revitalizar a } \\
\text { imagem do bibliotecário } \\
\text { significa imbricar, em } \\
\text { medidas iguais, a natureza } \\
\text { humanística e técnica do } \\
\text { conjunto de saberes que o } \\
\text { define como um profissional } \\
\text { da informação. }\end{array}$ \\
\hline & $\begin{array}{l}\text { Formação } \\
\text { profissional do } \\
\text { bibliotecário }\end{array}$ & $\begin{array}{l}\text { WALTER, } \\
\text { Maria Tereza } \\
\text { Machado Teles; } \\
\text { BAPTISTA, } \\
\text { Sofia Galvão }\end{array}$ & 2008 & $\begin{array}{l}\text { Apresenta aspectos que } \\
\text { difere a profissão, do que } \\
\text { distingue emprego e } \\
\text { trabalho e de que se } \\
\text { constitui o constructo de } \\
\text { competência profissional }\end{array}$ & $\begin{array}{l}\text { As escolas devem buscar } \\
\text { manter os currículos em } \\
\text { consonância com as } \\
\text { exigências mercadológicas, } \\
\text { mas atenta às necessidades } \\
\text { sociais, assim como são } \\
\text { importantes as iniciativas do } \\
\text { profissional em busca da } \\
\text { educação continuada. }\end{array}$ \\
\hline
\end{tabular}

\footnotetext{
${ }^{1}$ Selecionou-se essa base por ser ela específica em disponibilizar artigos na área da Ciência da Informação no Brasil, estudos esses fundamentados em atividades planejadas institucionalmente.

\begin{tabular}{l|c|c|c|c|c}
\hline (C) RDBCI: Rev. Digit. Bibliotecon. Cienc. Inf. & Campinas, SP & v.15 & n.2 & p. 289-307 & maio/ago. 2017 \\
\hline
\end{tabular}
}




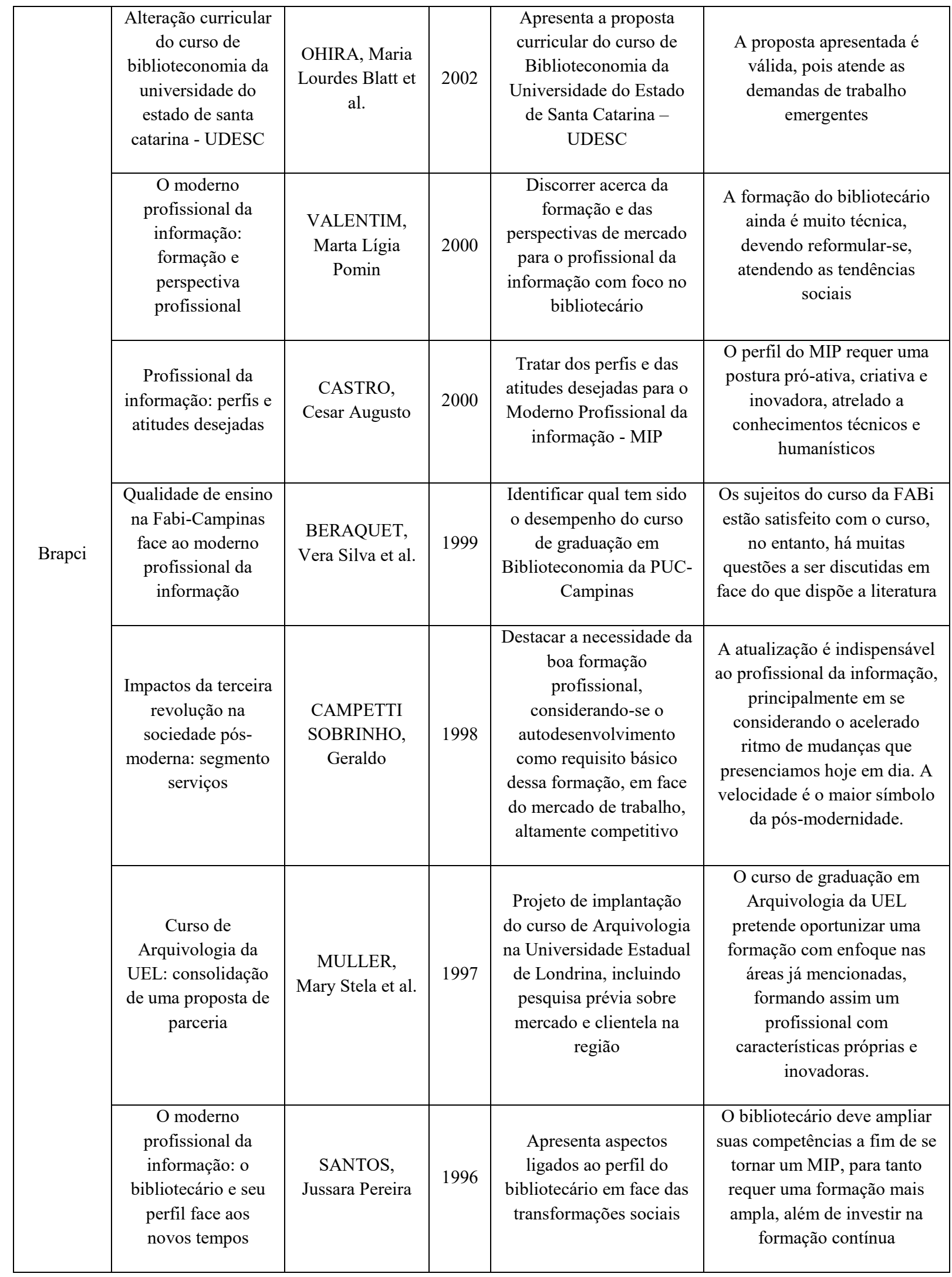

Fonte: o autor (2015).

\begin{tabular}{|c|c|c|c|c|c|}
\hline (C) RDBCI: Rev. Digit. Bibliotecon. Cienc. Inf. & Campinas, SP & v.15 & n. 2 & p. 289-307 & maio/ago. 2017 \\
\hline
\end{tabular}


Analisando a amostra de pesquisa investigada, constata-se, a princípio, que as publicações sobre a temática "MIP", iniciaram-se, no contexto brasileiro, no ano de 1996. Dentro dos dez artigos, o último ano em que foi publicada uma pesquisa sobre o MIP é o ano de 2010. O gráfico 1 expõe os dez artigos, considerando as datas de publicações.

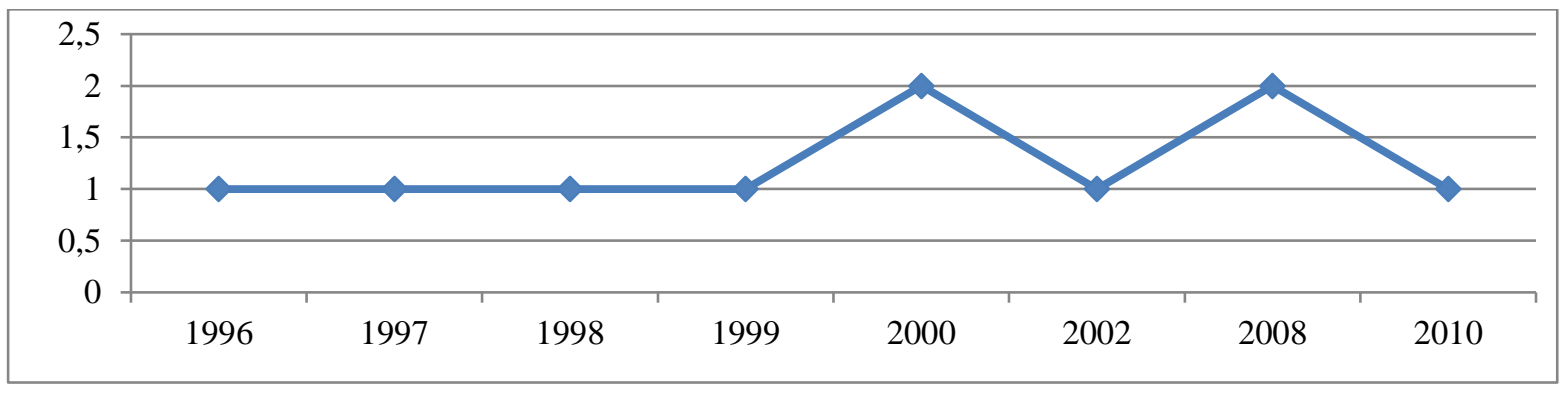

Gráfico 1. Número de artigos publicados ao longo dos anos, no Brasil Fonte: o autor (2015).

A leitura do gráfico acima permite constatar que as pesquisas começaram a ser realizadas no final da década de 1990. De 1996 a 1999, foram publicados ao todo, quatro artigos, um em cada ano. Em 2000, foram publicados dois artigos. Isso talvez seja justificado pela ocorrência, no ano 2000, do IV Encontro de Diretores das Escolas de Biblioteconomia e Ciência da Informação do Mercosul, realizado em Montevidéu, em que foram estabelecidas as competências do MIP. Em 2002, publicou-se mais um artigo; em 2008, dois artigos e, por fim, no ano de 2010, novamente, apenas um artigo.

Por meio das análises das publicações, detectam-se diferentes segmentos direcionados ao MIP. Entender quais profissionais se enquadra na categoria de MIP, faz-se necessário, a princípio, definir quem são os profissionais da informação. De acordo com o estudo de Castro (2000, p. 7), ao citar Le Coadic (1996, p. 106) ${ }^{2}$, tem-se que os profissionais da informação compreendem todos os sujeitos que adquirem informação registrada em diferentes suportes e através de critérios e técnicas científicas " [...] organizam, descrevem, indexam, armazenam e recuperam e distribuem essa informação em sua forma original ou como produtos elaborados a partir dela".

Por conseguinte, a pesquisa de Santos (1996, p. 23, grifo nosso) defendeu que profissionais da informação, de modo geral, são aqueles que possuem a informação como objeto de análise e trabalho, citando como exemplo: “[...] os arquivistas, museólogos, administradores, analistas de sistema, comunicadores, documentalistas e bibliotecários, além dos profissionais ligados à informática e às tecnologias da informação e às telecomunicações".

Ora, se assim for, os arquivistas também se inserem na categoria MIP. Analisando o foco de categoria profissional o qual as dez pesquisas analisadas se direcionaram, ou seja, em

${ }^{2}$ LE COADIC, Yves- Francois. A Ciência da Informação. Briquet de Lemos:Brasília,1996.

\begin{tabular}{c|c|c|c|c|c}
\hline (C) RDBCI: Rev. Digit. Bibliotecon. Cienc. Inf. & Campinas, SP & v.15 & n.2 & p. 289-307 & maio/ago. 2017 \\
\hline \multicolumn{6}{c}{$[296]$}
\end{tabular}


qual segmento (bibliotecário, arquivista, museólogo, etc.) o MIP foi direcionado nas pesquisas, constatamos os seguintes direcionamentos: MIP focado nos bibliotecários, focado nos arquivistas e não direcionado a profissionais específicos.

Os dados coletados da revisão de literatura permitem constatar que a maioria dos estudos, ou seja, oito deles (80\%) foram desenvolvidos relacionando o MIP ao bibliotecário. Um artigo (10\%) relacionou o MIP com o arquivista, e também, um artigo (10\%) não delimitou um profissional específico, mas tratou a temática MIP no âmbito dos profissionais da informação, em geral (gráfico 2).

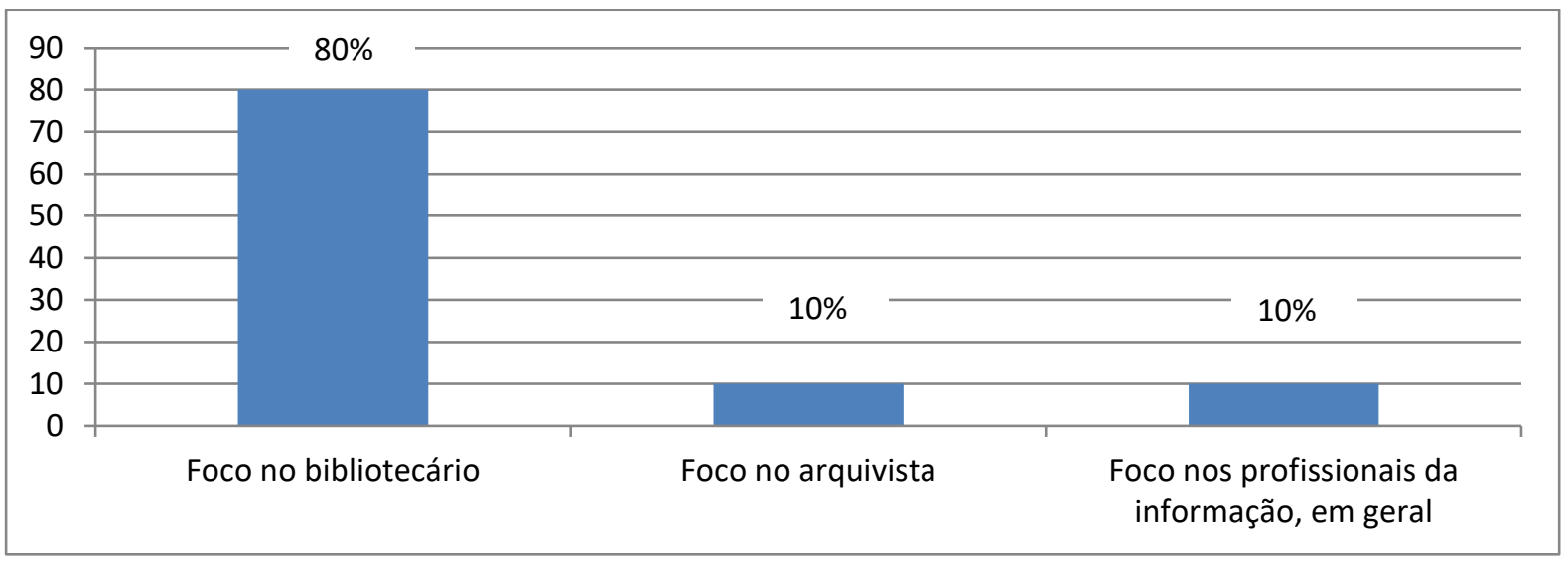

Gráfico 2. Direcionamentos abordados nos estudos: foco no bibliotecário, foco no arquivista e foco nos profissionais da informação, em geral

Fonte: o autor (2015).

Através da leitura desses resultados, pode-se constatar que a Biblioteconomia, no contexto brasileiro, vem desenvolvendo maior número de pesquisas sobre o MIP, discorrendo acerca da necessidade que os bibliotecários devem possuir em atualizar-se constantemente, adquirindo novas competências e perfis, tornando um profissional ativo, questionador, inovador e audacioso, por conseguinte, atingindo as características de MPI.

As pesquisas na área da Biblioteconomia são unânimes ao considerar a formação continuada como a alternativa mais viável para que os bibliotecários se modernizem. O estudo de Walter e Baptista (2008), por exemplo, aponta que o somatório das competências adquiridas com a prática diária e com investimentos na formação profissional continuada proporcionará, ao profissional, melhores condições para atuar no mercado da informação, ancorado em sólido embasamento teórico e prático.

Em linhas gerais, os oito artigos analisados, cuja temática foi direcionada ao bibliotecário, consideram também, como um dos pré-requisitos essenciais ao bibliotecário, dominar as tecnologias modernas, a fim de utilizá-las em favor da gestão e do tratamento da informação. Segundo Silveira (2008, p. 83), os bibliotecários ao atingirem a categoria de MIP, transformam-se em "[...] sujeitos que participam ativamente de todas as etapas do ciclo informacional e mantêm íntimo contato com as tecnologias da informação [...]”"

\begin{tabular}{c|c|c|c|c|c}
\hline (C) RDBCI: Rev. Digit. Bibliotecon. Cienc. Inf. & Campinas, SP & v.15 & n.2 & p. 289-307 & maio/ago. 2017 \\
\hline
\end{tabular}


O estudo de Valentim (2000) aponta alguns indicadores, que, segundo a autora, são imprescindíveis para que os bibliotecários exerçam todas as competências que lhe são atribuídas. Citam-se os seguintes:

a) remodelagem da unidade/sistema de informação, buscando uma interação profunda entre os atores deste cenário;

b) capacitação dos profissionais de informação, buscando o conhecimento necessário para atuar neste cenário;

c) vocação definida voltada para serviços informacionais, buscando o encantamento do cliente; e,

d) visualização da unidade/sistema de informação de forma crítica, buscando a melhoria contínua.

Alguns estudos, além de mencionarem as transformações sociais e a modificação de paradigma na Biblioteconomia, exigindo um profissional cada dia mais competente, também destacam o papel da formação acadêmica, levando em consideração a participação das escolas nesse contexto.

Na visão de Castro (2000, p. 10),

\begin{abstract}
A nossa preocupação quanto às mudanças paradigmáticas que estão ocorrendo no mundo da informação está em as escolas/cursos de Biblioteconomia absorverem ideias, valores e saberes sem atentarem para a realidade brasileira, permeada por graves problemas sociais, culturais e educacionais, dentre outros [...].
\end{abstract}

Por outro lado, o autor adverte para o fato de que, ao adotarem modismos e terminologias de outros campos de conhecimento apenas para configurarem a Ciência da Informação como ciência e os profissionais que nela atuam como profissionais da informação, podem, antes de trazerem contribuições significativas, fragilizarem a natureza, o papel, a função, as práticas e as teorias da área (CASTRO, 2000).

De acordo com os resultados obtidos da investigação de Madureira e Vilarinho (2010), as escolas de Biblioteconomia precisam se adaptar ao mercado atual, oferecendo disciplinas que condicionem o profissional a atuar junto a bibliotecas digitais, exercendo a prática bibliotecária além dos ambientes convencionais, como as bibliotecas físicas. Assim, o currículo ainda carece de disciplinas tecnológicas, o que prejudica a formação das competências relacionadas ao uso da tecnologia da informação e comunicação.

$\mathrm{Na}$ visão de muitos acadêmicos, os cursos vêm adentrando-se a essa realidade. No entanto, é preciso aproximar as práticas profissionais requeridas no mercado com o que é oferecido nas disciplinas acadêmicas (BERAQUET et al., 1999). 
Segundo Santos (1996), é preciso entender que os bibliotecários brasileiros “[...] estão saindo de sua área de domínio, segura e confortável (o documento escrito) e entrando no tratamento específico da informação [...]". Nesse âmago, eles tornam-se MIP, porém, para atingir esse fim, é preciso investir na formação continuada, assim como cabe às escolas de Biblioteconomia direcionar a formação, conforme a demanda de mercado, tornando visível a atuação bibliotecária em ambientes que vão além das unidades de informação.

Analisando o artigo direcionado para o arquivista, tem-se a pesquisa realizada por Muller (1997). Através de levantamentos, foram detectadas as demandas de trabalho existentes em um município, o que sustentou a estruturação do Curso de Arquivologia na referida cidade.

A autora constata por meio das necessidades das empresas da região que não basta formar um arquivista com perfil unicamente técnico. É preciso envolvê-lo com habilidades e competências mais amplas, a ponto de remetê-lo às características do MIP. Assim, o currículo do curso foi elaborado com o propósito de obter um profissional com base humanística e técnica, visando o moderno profissional da informação para o século XXI.

A autora discorre ao longo do artigo, a nova visão que os arquivistas vêm adquirindo ao longo dos tempos, perdendo-se o estereótipo de ser apenas "um guardador de papel". Ao contrário, o arquivista passa a atuar na gestão da informação, tendo em vista produzir conhecimento para a sociedade. Assim,

[...] o arquivista não pode ser confundido com os "archivists" de décadas anteriores, porquanto deve atuar não apenas em instituições públicas, mas em vários setores da sociedade, públicos ou privados, nos quais o gerenciamento de sistemas arquivísticos, quer sejam de particulares, de grupos, empresas, indústrias etc., se faça necessário (MULLER, 1997, p. 47).

A autora conclui a discussão teórica, frisando a respeito das possibilidades de atuação do arquivista no mercado de trabalho. Segundo a autora, o mercado exige, portanto, um profissional apto a trabalhar com a informação desde a produção, coleta, organização, interpretação, armazenamento, recuperação, disseminação e uso da mesma, utilizando como ferramenta a tecnologia disponível. Infere que as competências dos arquivistas permeiam o universo da Ciência da Informação, o que remete ao profissional adquirir status de MIP, a fim de se adaptar em meio às aceleradas transformações.

Por fim, o artigo de Campetti Sobrinho (1998), em vez de direcionar o perfil do MIP a profissionais específicos, como bibliotecário ou arquivistas, destaca a necessidade de todos aqueles que trabalham com a informação e estão inseridos na sociedade globalizada, remodelarem constantemente suas práticas, a fim de vencer os desafios impostos.

Em vez de enfatizar a necessidade de reformulação dos currículos acadêmicos, o autor foca, com mais especificidade, na formação continuada do profissional, que, como consequência viabilizará autodesenvolvimento ao profissional.

\begin{tabular}{c|c|c|c|c|c}
\hline (C) RDBCI: Rev. Digit. Bibliotecon. Cienc. Inf. & Campinas, SP & v.15 & n.2 & p. 289-307 & maio/ago. 2017 \\
\hline \multicolumn{6}{c}{$[299]$}
\end{tabular}


Destaca que os profissionais precisam adquirir competências gerenciais, com vistas a atuar de forma pró-ativa sobre os problemas; é importante que tenham capacidade de análise e crítica, contribuindo na tomada de decisões; é necessário serem criativos, a fim de propor respostas consistentes aos problemas que surgem, e, em suma, esses profissionais precisam se atualizar constantemente, haja vista atenderem demandas complexas e diversificadas.

Após análise da literatura, evidenciaram-se poucos estudos sobre o MIP, desenvolvidos por pesquisadores da área da Arquivística. A partir de então, recorreu-se à segunda etapa metodológica, sustentada por estudo documental. A princípio, pergunta-se: será que os currículos das escolas de Arquivologia do Brasil estão oferecendo disciplinas voltadas para garantir a consolidação das quatro competências do MIP? A análise dos currículos dessas escolas, realizada a seguir, possui essa pretensão.

\section{O ARQUIVISTA E SUA RELAÇÃO COM O MODERNO PROFISSIONAL DA INFORMAÇÃO: ENFOQUE NA FORMAÇÃO CURRICULAR}

De acordo com o Conselho Nacional de Arquivos (CONARQ), o Brasil possui 16 escolas de Arquivologia, distribuídas em diferentes regiões brasileiras, conforme ilustrado no gráfico 3 .

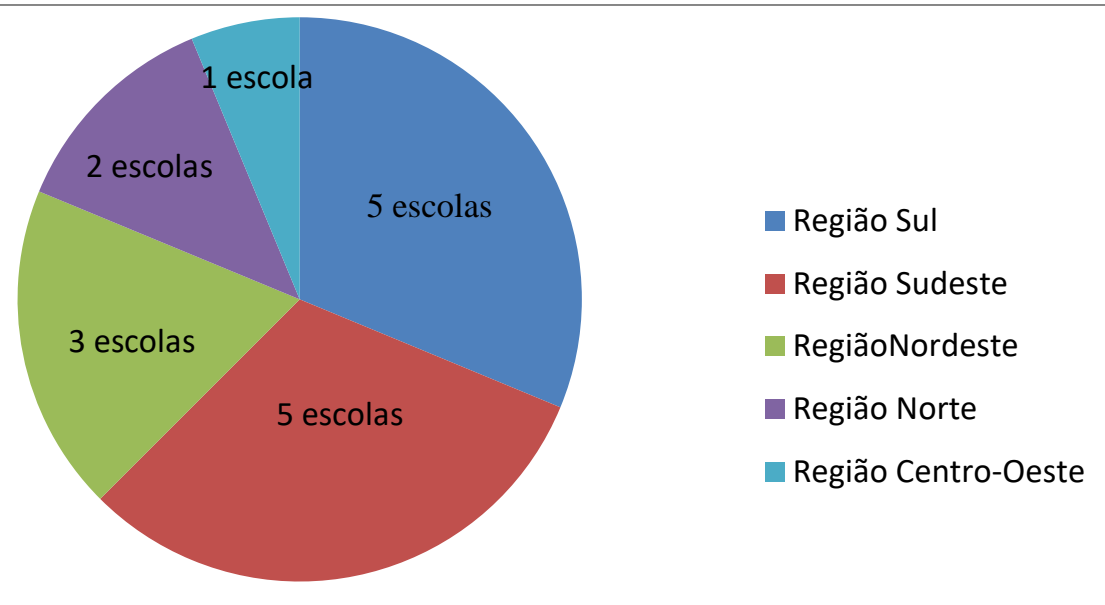

Gráfico 3. Distribuição das escolas de Arquivologia, por regiões brasileiras Fonte: o autor (2015, com base no CONARQ).

Na região Sul as escolas de Arquivologia estão localizadas nas seguintes universidades: Universidade Federal de Santa Maria (UFSM), Universidade Estadual de Londrina (UEL), Universidade Federal do Rio Grande do Sul (UFRGS), Universidade Federal do Rio Grande (FURG) e Universidade Federal Santa Catarina (UFSC). Na região sudeste as escolas situamse: Universidade Federal Fluminense (UFF), Universidade Federal do Estado do Rio de Janeiro (UNIRIO), Universidade Federal do Espírito Santo (UFES), Universidade Estadual Paulista (UNESP/MARÍLIA) e Universidade Federal de Minas Gerais (UFMG). No Centro-Oeste há uma escola situada na Universidade de Brasília (UNB). No Nordeste brasileiro localizam-se

\begin{tabular}{l|c|c|c|c|c}
\hline (C) RDBCI: Rev. Digit. Bibliotecon. Cienc. Inf. & Campinas, SP & v.15 & n.2 & p. 289-307 & maio/ago. 2017 \\
\hline
\end{tabular}


três escolas: Universidade Federal da Bahia (UFBA), Universidade Estadual da Paraíba (UEPB) e Universidade Federal da Paraíba (UFPB). Por fim, na região Norte, são oferecidos dois cursos situados nas seguintes universidades: Universidade Federal do Amazonas (UFAM) e Universidade Federal do Pará (UFPA).

Nota-se que a Região Sul e Sudeste contempla o maior número de escolas de Arquivologia. Assim, visando aferir representatividade à amostra desta pesquisa, delimitou-se a serem estudados apenas os currículos das escolas dessas duas regiões, resultando em uma amostra constituída por dez escolas.

Para análise dos currículos das escolas tendo em vista perceber o enfoque que tem sido dado à formação do arquivista no contexto do MIP, foram analisadas disciplinas que contemplam aspectos relacionados a cada uma das quatro competências do MIP: competências de comunicação, técnico-científica, gerenciais e sociais e políticas.

No que se refere às competências de comunicação e expressão, em todos os cursos foram identificadas disciplinas que contemplam assuntos que tornam os profissionais capacitados a transmitirem informação, através de processos de comunicação.

De modo geral, os currículos oferecem disciplinas relacionadas à linguística e produção textual, como as disciplinas "Práticas de Redação" e "Leitura e Produção de textos"; também oferecem disciplinas que demonstram a dinamicidade da informação e sua distribuição através de linguagens e canais de comunicação, como as disciplinas "Introdução à Comunicação", "Teorias da Comunicação" e "Leitura e Informação". No que se refere ao domínio de outras línguas, no contexto da Arquivística, destacam-se as disciplinas "Inglês Instrumental I e II" e "Língua espanhola". Também se observaram disciplinas que capacitam o acadêmico a ter relações saudáveis na convivência em equipe, como na disciplina "Relações humanas no trabalho" (Quadro 2).

Quadro 2. Identificação das disciplinas voltadas para consolidar a competência comunicação e expressão

\begin{tabular}{|l|l|}
\hline \multicolumn{1}{|c|}{ COMPETÊNCIA } & \multicolumn{1}{|c|}{ DISCIPLINAS } \\
\hline \multirow{2}{*}{ COMUNICAÇÃO E EXPRESSÃO } & $\begin{array}{l}\text { Informação e linguagens documentárias; Inglês } \\
\text { Instrumental I e II; Introdução à Comunicação; Leitura e } \\
\text { produção de textos; Práticas de redação; francês } \\
\text { instrumental; língua espanhola; teorias da comunicação; } \\
\text { Teoria da comunicação; Introdução à comuniçaco; } \\
\text { Comunicação e negociação; Produção textual; Relações } \\
\text { humanas no trabalho; e Leitura e informação. }\end{array}$ \\
\hline
\end{tabular}

Fonte: o autor (2015).

As competências de comunicação e expressão, em linhas gerais, são aquelas que tornam o profissional capaz de "[...] Elaborar produtos de informação (bibliografias, catálogos, guias, 
índices, disseminação seletiva da informação, etc.); Planejar e executar estudos de usuários dos sistemas de informação [...]" (VALENTIM, 2000, p. 21).

Percebe-se que os currículos, ao oferecerem as disciplinas supracitadas estão preocupados em inserir no mercado um profissional que tenha facilidade em interagir com outras pessoas, adapte-se a diferentes contextos e consiga viabilizar, através dos canais e das linguagens documentárias, a disseminação da informação.

As competências técnico-científicas são aquelas específicas do trabalho de um profissional da informação, ou seja, compreende o conjunto de atividades arroladas ao tratamento e gerenciamento da informação, de modo que ela se torne recuperável e apta a sanar necessidades, transformando-se em conhecimento para o usuário. Possuindo competências técnico-científicas, cabe ao profissional:

[...] Desenvolver e executar o processamento de documentos em distintos suportes, unidades e serviços de informação; Selecionar, registrar, armazenar, recuperar e difundir a informação gravada em qualquer meio para os usuários de unidades, serviços e sistemas de Informação [...] (VALENTIM, 2000, p. 19).

A pesquisa documental nos dez currículos permitiu constatar o enfoque da formação na atividade técnica e prática que permeia o cotidiano de um arquivista ou profissional da informação que irá trabalhar com informação arquivística, informação essa oriunda das atividades orgânicas de uma instituição. A maioria das disciplinas visa fomentar a competência técnico-científica. Foi possível identificar como principais disciplinas técnicas do currículo, 40 disciplinas, conforme expresso no quadro 3.

Quadro 3. Identificação das disciplinas voltadas para consolidar a competência técnico-científicas

\begin{tabular}{|l|l|}
\hline COMPETÊNCIA & \multicolumn{1}{|c|}{ DISCIPLINAS } \\
\hline & Prática e produção de documentos; Fundamentos da Arquivologia; \\
& Arquivística aplicada; Avaliação de documentos; Arranjo e descrição \\
de documentos; Conservação; Arquivo corrente; Arquivo \\
& Intermediário; Arquivo permanente; Informática documentária; \\
& Diplomática; Análise documentária; Indexação; Normalização \\
& documentária; Banco de dados aplicado à Arquivística; Gestão \\
& Arquivística de documentos digitais; Fundamentos da Ciência da \\
& Informação; Paleografia; Documentos digitais; Estatística básica; \\
& Arquivos especializados; Normalização; Metadados; Registros e \\
TÉCNICO-CIENTÍfICA & suportes do conhecimento; Autenticidade digital; Gerenciamento \\
& eletrônico de documentos; Preservação digital; Repositórios digitais; \\
& Difusão de arquivos; Prática arquivística; Introdução à informática; \\
& Fundamentos da Ciência da Informação; Recuperação da informação \\
& em arquivos; Gestão da Informação e do Conhecimento; Fontes de \\
& Informação; Gestão da Qualidade em Unidades de Informação; \\
& Editoração; Organização de Unidades de Informação; Arquivometria; \\
& e Estudo de uso e de usuário. \\
\hline
\end{tabular}

Fonte: o autor (2015).

Pela análise das disciplinas inseridas no quadro 2, nota-se que a formação acadêmica está direcionada para formar um arquivista híbrido, que dialogue com outras áreas de forma 
interdisciplinar, gerenciando documentos em diferentes suportes, sobretudo diante dos documentos disponibilizados em ambiente digital. Embora se perceba uma especificação do trabalho, ou seja, o arquivista lida com a informação arquivística, seja ela em diferentes suportes, infere-se que a atuação profissional, pelo menos o que vem sendo ensinado nas escolas analisadas, objetiva formar um arquivista que possa atuar em outros segmentos profissionais, atuando na gestão de documentos eletrônicos, seja em unidades de informação, como em organizações que priorizem a informação como insumo básico de desenvolvimento.

No que se refere às competências gerenciais, é comum perceber essa competência em qualquer prática profissional. No ramo da Ciência da Informação, para ser um MIP, o profissional deve possuir características voltadas para a gestão, abrangendo, holisticamente, as ações de "[...] Formular, dirigir, administrar, organizar e coordenar unidades, sistemas, projetos e serviços de informação [...]" (VALENTIM, 2000, p. 20).

Analisando os currículos das escolas de Arquivologia da região Sul e Sudeste do Brasil, constatou-se 10 principais disciplinas voltadas para fomentar as competências gerenciais (Quadro 4).

Quadro 4. Identificação das disciplinas voltadas para consolidar as competências gerenciais

\begin{tabular}{|l|l|}
\hline COMPETÊNCIA & \multicolumn{1}{|c|}{ DISCIPLINAS } \\
\hline \multirow{3}{*}{ GERENCIAIS } & $\begin{array}{l}\text { Introdução à Administração; Gerência em Arquivo I e II; Métodos } \\
\text { e procedimentos administrativos; Organização, métodos e } \\
\text { sistemas; Administração contemporânea; Gestão de documentos I } \\
\text { e II; Administração aplicada à Ciência da Informação; e Teoria } \\
\text { Geral da Administração. }\end{array}$ \\
\hline
\end{tabular}

Fonte: o autor (2015).

Algumas disciplinas apresentam as competências de gestão no âmbito dos arquivos ou unidades de informação, como as disciplinas "Gestão de Arquivos I e II", "Gestão de documentos I e II" e “Administração aplicada à Ciência da Informação”. Outras já apresentam as técnicas gerenciais conforme fundamentadas pela ciência administrativa. Compreendem as seguintes disciplinas: "Introdução à Administração", "Métodos e procedimentos administrativos", "Organização, métodos e sistemas", "Administração contemporânea" e "Teoria Geral da Administração".

Por fim, ao discorrer acerca das competências sociais e políticas do MIP, essas competências afloram para o papel social do profissional, devendo expandir seu fazer além das paredes da unidade de informação. Assim, Valentim (2000, p. 21) disserta que, nesse quesito, caberá ao profissional fomentar uma atitude "[...] aberta e interativa com os diversos atores sociais (políticos, empresários, educadores, trabalhadores e profissionais de outras áreas, instituições e cidadãos em geral) que configuram o atual ciclo informacional [...]”". 
Analisando os currículos dos cursos de Arquivologia, percebe-se que oito disciplinas disponibilizam aos alunos conteúdos relacionados ao papel social e político do arquivista e do arquivo na sociedade (Quadro 5).

Quadro 5 - Identificação das disciplinas voltadas para consolidar a competência Sociais e Políticas

\begin{tabular}{|c|l|}
\hline COMPETÊNCIA & \multicolumn{1}{c|}{ DISCIPLINAS } \\
\hline SOCIAIS E POLÍTICAS & $\begin{array}{l}\text { Arquivo, patrimônio e memória; Ética profissional aplicada à } \\
\text { Arquivologia; Memória e patrimônio; Atuação profissional em } \\
\text { Arquivologia; Brasil contemporâneo: sociedade, cultura, economia } \\
\text { e política; Política e legislação em arquivos; Ação cultural; e } \\
\text { Educação patrimonial. }\end{array}$ \\
\hline
\end{tabular}

Fonte: o autor (2015).

Essas disciplinas apresentam aspectos relacionados ao desenvolvimento histórico, social e econômico das nações, enfocando a presença da cultura e a importância que o arquivo desempenha como unidade que viabiliza preservação e disseminação da memória cultural e social de uma dada localidade.

Algumas disciplinas também estão voltadas para o compromisso, responsabilidade e missão do arquivista junto ao desenvolvimento social. Ou seja, através do compromisso com a ética profissional, atuando de forma civilizada e concretizando de forma legal suas competências, certamente, o arquivista proporciona desenvolvimento para a sociedade, pois consegue gerenciar informação de qualidade, buscando produzir conhecimentos inovadores que resolvam inúmeros problemas do cotidiano.

Com efeito, a análise curricular permitiu constatar que o comprometimento com as causas sociais e políticas foi a competência que possui menos representatividade nas disciplinas dos cursos das escolas analisadas. Acredita-se ser um processo complexo demonstrar o lado social do profissional em uma sociedade que ainda reconhece esses profissionais como aqueles que atuam, unicamente, em unidades de informação, organizando livros e documentos. No entanto, conforme defendido por Ribas e Ziviane (2007), é preciso unir esforços no sentido de que podemos transformar a realidade, à medida que utilizarmos nossas potencialidades para tornar a sociedade mais democrática, igualitária e inclusiva.

\section{4 À GUISA DE CONCLUSõES}

Através deste estudo, analisaram-se as competências do MIP relacionando-os ao arquivista, tendo como parâmetro de análise a Literatura Arquivística e a formação curricular. Por meio da análise na literatura sobre MIP, é possível concluir que a maioria dos estudos realizados (80\%), comparam o MIP ao bibliotecário. A literatura é escassa (10\%) ao direcionar o MIP ao arquivista, e também são escassos os estudos que abordam o MIP sem direcionar a profissionais específicos (10\%). 
Quanto à análise das competências do MIP conforme a formação acadêmica proporcionada pelas dez escolas analisadas, conclui-se que as escolas, em linhas gerais, disponibilizam disciplinas, cujo enfoque curricular contempla as quatro competências do MIP. Logo, inferimos que as escolas reconhecem a necessidade de ampliar as competências dos arquivistas, a ponto de eles se tornarem MIPs, haja vista adequarem-se aos novos desafios impostos pelo mercado de trabalho da atualidade.

De certo modo, observou-se uma grande escassez de pesquisas direcionadas ao MIP, não sendo discutido com grande frequência na atualidade. Talvez esse fato se deva às limitações de busca dos artigos. Por isso, recomenda-se a realização de pesquisas bibliográficas mais aprofundadas, utilizando outras bases de dados, de modo a ampliar o número de publicações a serem analisadas sobre a temática em apreço.

Recomenda-se, que seja realizado um estudo in loco, investigando a opinião dos empresários a respeito das competências do moderno profissional. No que se refere à formação acadêmica, é preciso que as escolas continuem inovando seus currículos frequentemente, conforme disposto por Ribas e Ziviani (2007, p. 54): “[...] Acredita-se que o processo de formação e qualificação desse profissional pode ser apreendido como uma realidade dinâmica e inacabada, fruto das transformações advindas da contemporaneidade [...]", assim como também foi proclamado por Johnson (1998, p. 15), ao mencionar que as escolas precisam, antes de mais nada, “[...] acelerar suas habilidades de enfrentar as mudanças e, em particular, de lançar novos talentos e energia, de modo a desenvolver novas disciplinas e cursos de forma rápida e periódica". Esses serão desafios permanentes impostos aos profissionais pela própria evolução social.

\section{REFERÊNCIAS}

ARAÚJO, Carlos Alberto Ávila. Arquivologia, Biblioteconomia, Museologia e Ciência da Informação: o diálogo possível. Brasília: Briquet de Lemos, 2014.

BERAQUET, Vera Silva et al. Qualidade de ensino na fabi-campinas face ao moderno profissional da informação. Transinformação, Campinas, v. 11, n. 1, p. 63-69, jan./abr. 1999.

BURKE, Peter. Uma história social do conhecimento: da enciclopédia à wikipédia. Rio de Janeiro: J. Zahar, 2012.

CAMPETTI SOBRINHO, Geraldo. Impactos da terceira revolução na sociedade pósmoderna: segmento serviços. Revista de Biblioteconomia de Brasília, Brasília, v. 22, n.2, p.211-220, 1998.

CASTRO, Cesar Augusto. Profissional da informação: perfis e atitudes desejadas.

Informação \& Sociedade: Estudos, João Pessoa, v. 10, n. 1. 2000. 
CONSELHO NACIONAL DE ARQUIVOS (CONARQ). Cursos de Arquivologia no Brasil. Rio de Janeiro, 2015. Disponível em: <http://www.conarq.arquivonacional. gov.br/links/389-cursos-de-arquivologia-no-brasil.html>. Acesso em: 20 jun. 2014.

COOK, T. A ciência arquivística e o pós-modernismo: novas formulações para conceitos antigos. InCID: Revista Ciência da Informação e Documentação, Ribeirão Preto, v. 3, n. 2, p. 3-27, jul./dez. 2012. Disponível em: < http://www.revistas.usp.br/incid/article/view/48651/ 52722>. Acesso em: 16 jun. 2014.

JARDIM, José Maria; FONSECA, Maria Odília. Estudos de usuários em arquivos: em busca de um estado da arte. [sine loco], DataGramaZero - Revista de Ciência da Informação, Rio de Janeiro, v.5, n.5, out. 2004. Disponível em: 〈http://www.dgz.org.br/out04/Art_04.htm>. Acesso em: 6 maio 2015.

JOHNSON, Ian. Desafios para o desenvolvimento Profissional na "Sociedade da Informação": algumas respostas das Escolas de Biblioteconomia e Estudos de Informação na Grã-Bretanha. Informação \& Informação, Londrina, v. 3, n. 2, p. 7-18, jul./dez. 1998.

LOPES, Luis Carlos. A nova arquivística na modernização administrativa. 2. ed. Brasília: Annabel Lee, 2009.

MADUREIRA, Helania Oliveira; VILARINHO, Lúcia Regina Goulart. A formação do bibliotecário para atuar em bibliotecas virtuais: uma questão a aprofundar. Perspectivas em Ciência da Informação, Belo Horizonte, v. 15, n. 3, 2010.

MASON, R. O. What is an information professional? Journal of Education for Library and Information Science, Chicago, v. 31, n. 2, p. 122-138, 1990.

MC GARRY, Kevin. O contexto dinâmico da informação: uma análise introdutória. Brasília: Briquet de Lemos, 1999.

MULLER, Mary Stela et al. Curso de arquivologia da UEL: consolidação de uma proposta de parceria. Informação \& Informação, Londrina, v.2, n.1, p.45-66, jan./jun. 1997.

PONJUÁN DANTE, Glória. Does the Modern Information Professional have a Life Cycle? FID News Bulletin, Bruxelas, v. 43, n. 3, p. 61, mar. 1993.

PONJUÁN DANTE, Glória. Perfi 1 del profesional de información del nuevo milenio. In: VALENTIM, Marta Lígia (Org.). Profissionais da informação: formação, perfil e atuação profissional. São Paulo: Polis, 2000. p. 91-105.

RIBAS, Cláudia S. da Cunha; ZIVIANI, Paula Ziviani. O profissional da informação: rumos e desafios para uma sociedade inclusiva. Informação \& Sociedade: Estudos, João Pessoa, v.17, n.3, p.47-57, set./dez. 2007. Disponível em: <http://www.ies.ufpb.br/ojs/index.php/ies /article/viewFile/638/1614>. Acesso em: 12 maio 2015.

SANTOS, Jussara Pereira. O moderno profissional da informação: o bibliotecário e seu perfil face aos novos tempos. Informação \& Informação, Londrina, v.1, n.1, p.5-13, jan./jun.

\begin{tabular}{l|c|c|c|c|c}
\hline (C) RDBCI: Rev. Digit. Bibliotecon. Cienc. Inf. & Campinas, SP & v.15 & n.2 & p. 289-307 & maio/ago. 2017 \\
\hline
\end{tabular}


1996. Disponível em: < http://www.uel.br/revistas/uel/index.php/informacao/ article/view/1613>. Acesso em: 12 maio 2015.

SILVEIRA, Fabrício José Nascimento da. O bibliotecário como agente histórico: do "humanista" ao "moderno profissional da informação". Informação \& Sociedade: Estudos, João Pessoa, v.18, n.3, p. 83-94, set./dez. 2008.

SMIT, Johanna W. O profissional da informação e sua relação com as áreas de Biblioteconomia/Documentação, Arquivologia e Museologia. In: VALENTIM, Marta Lígia (Org.). Profissionais da informação: formação, perfil e atuação profissional. São Paulo: Polis, 2000. p. 119-134.

SOLLA PRICE, D. J. Little science, big science. New York: Columbia University Press, 1993.

TOGNOLI, Natália. A informação no contexto arquivístico: uma discussão a partir dos conceitos de informação-como-coisa e informação orgânica. Informação Arquivística, Rio de Janeiro, RJ, v. 1, n. 1, p. 113-122, jul./dez., 2012. Disponível em: <http://www.aaerj.org. br/ojs/index.php/informacaoarquivistica/arti cle/vie w/8/7>. Acesso em: 20 maio 2014.

VALENTIM, Marta Lígia Pomin. O moderno profissional da informação: formação e perspectiva profissional. Encontros Bibli: Revista de Biblioteconomia e Ciência da Informação, Florianópolis, n.9, p.16-27, jun. 2000.

WALTER, Maria Tereza Machado Teles; BAPTISTA, Sofia Galvão. Formação profissional do bibliotecário. Encontros Bibli: Revista Eletrônica de Biblioteconomia e Ciência da Informação, Florianópolis, n. 25, $1^{\circ}$ sem. 2008. Disponível em: 〈https://periodicos.ufsc.br/ index.php/eb/article/view/1518-2924.2008v13n25p84>. Acesso em: 21 maio 2014.
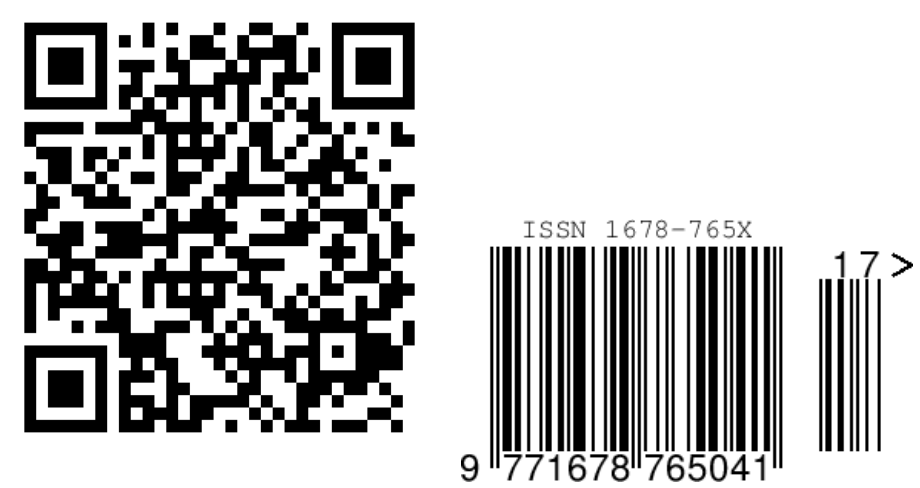